\title{
Organization Studies
}

http://oss.sagepub.com

\section{Toward a (Pragmatic) Science of Strategic Intervention: Design Propositions for Scenario Planning \\ Gerard P. Hodgkinson and Mark P. Healey \\ Organization Studies 2008; 29; 435 \\ DOI: $10.1177 / 0170840607088022$}

The online version of this article can be found at:

http://oss.sagepub.com/cgi/content/abstract/29/3/435

\section{Published by:}

(3)SAGE

http://www.sagepublications.com

On behalf of:

European Group for Organizational Studies

Additional services and information for Organization Studies can be found at:

Email Alerts: http://oss.sagepub.com/cgi/alerts

Subscriptions: http://oss.sagepub.com/subscriptions

Reprints: http://www.sagepub.com/journalsReprints.nav

Permissions: http://www.sagepub.co.uk/journalsPermissions.nav

Citations http://oss.sagepub.com/cgi/content/refs/29/3/435 


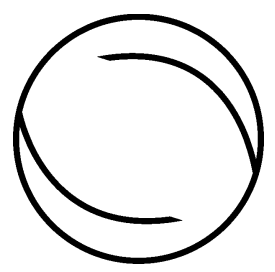

Gerard P.

Hodgkinson

Leeds University

Business School, UK

Mark P. Healey

Leeds University

Business School, UK

\section{Toward a (Pragmatic) Science of Strategic Intervention: Design Propositions for Scenario Planning}

\author{
Gerard P. Hodgkinson and Mark P. Healey
}

Organization

Studies

29(03): 435-457

ISSN 0170-8406

Copyright (C) 2008

SAGE Publications

(Los Angeles,

London, New Delhi

and Singapore)

\begin{abstract}
An enduring problem confronting design science is the question of how to distil design principles and propositions in contexts where only limited evidence has accrued directly in connection with the design problem at hand. This article illustrates how researchers can address this challenge by recourse to well-established bodies of basic theory and research in the wider social and organizational sciences that suggest robust design options. Adopting this approach, we draw upon the insights of social identity theory, self/social categorization theory and the Five Factor Model of human personality from the field of personality and social psychology to distil a series of propositions to inform the design of scenario planning interventions, centred on team composition and the facilitation process. In so doing, our article exemplifies the benefits of adopting a pragmatic science approach to the design of processes that promote organizational change and development, thus adding to the growing design science movement.
\end{abstract}

Keywords: design science, five factor model of personality, group cognition, organizational change and development, pragmatic science, scenario planning, self/social categorization theory, social identity theory, team composition

A fundamental challenge confronting the field of management and organization studies is the question of how to connect its scientific endeavours to the business of organization design, especially the design of processes that promote organizational change and development (see Dunbar and Starbuck 2006). This article illustrates how designers can address this challenge in contexts where only limited scientific evidence has accrued directly in connection with the design problem at hand, by drawing upon pertinent, well-established basic theory and research in order to distil robust design principles and propositions. Specifically, drawing on two major bodies of theory and research from the field of personality and social psychology, namely, social identity theory (Tajfel and Turner 1979) and related conceptions of self/social-categorization (Turner 1985; Turner et al. 1987) and the Five Factor Model of human personality (Digman 1990; McCrae and Costa 1987), we distil a series of propositions for the design of scenario planning interventions, centred on team composition and the facilitation process. Proponents of scenario planning claim it has a vital role to play in helping organizations develop the capability to anticipate uncertain futures, thus increasing their chances of long-term survival (e.g. van der Heijden et al. 2002; Schwarz 1991). However, the evidence base underpinning scenario planning is 
currently inadequate for design purposes, primarily comprising anecdotal case accounts by practitioners (for a notable exception see Schoemaker 1993).

Despite the recent resurgence of interest in design science, organization theorists and researchers remain equivocal regarding how to incorporate basic theory and research into the design process. On one hand, some scholars have argued that design solutions should emerge from the design process, that design is necessarily a voyage of discovery (see Boland and Collopy 2004; Schein 1987). According to this view, designers can undertake design activities and generate workable solutions without having a fully formed theoretical understanding of the organizational components or systems they are designing. Rather, theoretical understanding develops through active experimentation in the field, which in turn provides insights to inform future designs. On the other hand, several commentators have recently argued that extant theory and research in organization science, and indeed the social sciences more widely, should play a central role in informing design activities and the generation of design solutions. Dunbar and Starbuck (2006: 171), for instance, suggest that, 'for organization design to have a scientific base, research must develop concepts and propositions that suggest design options', such that 'social science knowledge can relate to organizational practice'. Van Aken (2004: 226) similarly argues, 'the mission of (academic) research in [design science] is to develop scientific knowledge to support the design of interventions or artefacts by professionals'. Likewise, Romme and Endenburg (2006) argue that organization theory and research should provide the theoretical foundations for design and that the insights from subsequent design activity should feed back into organization science. They advocate 'developing construction principles and design rules grounded in organization science as well as on organizational solutions implemented and tried out in real-life settings' (Romme and Endenburg, 2006: 287). Indeed, much of the recent organization design literature has been concerned with how organization science might best connect with organization design, through the elaboration of construction principles, design rules and propositions with explicit design implications. However, fundamental questions remain concerning the precise nature and function of these design aids.

Beginning the design process with the act of designing is problematic because it runs the risk of divorcing practice from basic research (Anderson et al. 2001). However, starting the design process by distilling principles and propositions from basic research can also be problematic because choosing appropriate bodies of work to inform design principles is potentially arbitrary, which might lead to misguided choices (see Romme and Endenburg 2006).

In order to gain valid and reliable design insights from basic research (i.e. ones that will maximize the likelihood of sound solutions), designers must draw upon robust bodies of work grounded in rigorous theory and evidence relevant to focal design goals. However, two issues arise when seeking to inform design with organization science. First, this approach emphasizes the importance of choosing bodies of work that connect closely to the design goals at hand, specifically those bodies of work that elucidate fundamental mechanisms that produce the outcomes of interest (Simon 1969; van Aken, 2004). Second, choosing basic science to address design goals necessitates a clear understanding of the 
goals of design, which itself can be problematic because design goals may be unclear at the outset of the design process (Dunbar and Starbuck 2006).

The evidence-informed approach to management research, which seeks to distil actionable principles from systematic reviews of prior studies (e.g. Tranfield et al. 2003), offers a powerful basis for meeting design challenges by recourse to well-established bodies of research. However, the evidence-informed approach is problematic in many potential design science applications, because the modus operandi of systematic review is to gather for systematic analysis and synthesis articles that have investigated empirically the specific design challenge at hand. In many situations confronting would-be designers, such an evidence base does not exist. This article illustrates how researchers can develop normative design propositions in such situations, with reference to the case of scenario planning.

\section{Scenario Planning in Organizations}

Scenario planning techniques have enjoyed immense popularity in recent years as a basis for intervening in the strategic management process. A recent UK survey showed that over a third of organizations use scenario planning in their strategizing (Hodgkinson et al. 2006), and earlier surveys have shown its usage is similarly widespread in mainland Europe (Malaska 1985) and the USA (Linneman and Klein 1983). However, there have been very few systematic attempts to evaluate its efficacy. Rather, as noted above, case studies dominate the literature, written by advocates attributing apparently positive outcomes for the organizations concerned to the scenario planning process (see, e.g., Ringland 2006; van der Heijden 1996; van der Heijden et al. 2002; Wack 1985a,b).

Although the burgeoning literature supportive of scenario planning is encouraging from an advocacy standpoint, it is inadequate from a design science perspective, for several reasons. First, since the evidence base primarily comprises anecdotal case accounts authored by practitioners, it has been more effective in legitimizing and justifying scenario planning than in scrutinizing rigorously the behavioural conditions and causal mechanisms that might enable scenariobased techniques to yield positive outcomes. In turn, this basic lack of understanding of the properties desirable in scenario planning makes effective design difficult. Second, since much of the scenario planning literature stems from the retrospective accounts of practising advocates, the insights provided by this body of work stem necessarily from 'insider inquiry' (i.e. inquiry conducted by individuals with a significant vested interest in the phenomena of study), as opposed to 'outsider inquiry' (i.e. research undertaken from a more dispassionate standpoint). As noted by Evered and Louis (1981: 392), sole reliance on insider inquiry can result in knowledge that suffers from 'dubious precision, rigor, or credibility', distorted by the values and purposes of the insider, thus reducing its value for informing future design efforts. To redress the inadequacies of the current evidence base underpinning the practice of scenario planning, it is vital that researchers generate design options grounded in scientifically rigorous concepts, theory and evidence, going well beyond the mere propagation of popularist management practices. 


\section{Cognitive Goals of Scenario Planning}

The fundamental premise underpinning modern scenario planning practices is that multiple scenario analysis represents an effective means of evincing adaptive cognitive change (Schoemaker 1993; van der Heijden et al. 2002). These claims are significant, given the evidence that decision makers' mental models can fail to change adequately and sufficiently quickly to reflect environmental shifts, i.e. cognitive inertia (Barr et al. 1992; Hodgkinson 1997; Reger and Palmer 1996). Techniques that might help decision makers update, broaden and realign thinking about their organization's strategic position and priorities thus have a potentially important role to play in alleviating such inertia and aiding organizational adaptability.

Proponents assert that scenarios act as a 'cognitive device' (van der Heijden 1996: 51) that leads actors to question and update their mental models of their organizations' competitive environment and strategic position. In this connection, scenarios are 'script-like narratives that paint in vivid detail how the future might unfold in one direction or another' (Russo and Schoemaker 1992: 13). Wack (1985a: 84) notes that when Royal Dutch/Shell used scenarios to help anticipate the downturn in world oil prices in the 1970s, the aim was 'to design scenarios so that managers would question their own model of reality and change it when necessary'. De Geus (1988: 71) has similarly argued that the critical goal of using scenario-based techniques is to "change ... the mental models that decision makers carry in their heads.' ${ }^{1}$

To achieve these cognitive outcomes, participants typically construct positive, negative and status quo scenarios that depict strategically important variables (e.g. industry structure, product technology) taking divergent forms (e.g. industry deregulation versus regulation; technological obsolescence versus technological continuity). Decision makers then test the robustness of present and/or potential strategies under the various environmental conditions depicted in the scenarios, analogous to the way that aeronautical engineers test the structural integrity of aircraft designs by subjecting them to extreme airflows in wind tunnels (van der Heijden 1996). Advocates claim that by challenging decision makers' assumptions and beliefs concerning the robustness of their strategies, scenario planning helps to equip organizations to withstand turbulent environmental conditions better.

\section{Importance of Team Design in Scenario Planning Exercises}

Scenario planning takes many forms but is, in the main, a group activity, almost exclusively carried out by bespoke project teams (see, e.g., van der Heijden 1996; van der Hiejden et al. 2002; Ringland 2006). Hence, we focus on those interventions where groups of decision makers come together to construct and analyse scenarios. Organizations typically undertake such major projects over several weeks, sometimes months, in the form of workshops, meetings and planning activities. Often the process is led and managed by internal or external facilitators and involves specialist consultants or futurists. In practice, the 
design of scenario planning processes, as with other forms of strategy-making activity, is the product of a negotiated order (Eden and Ackermann 1998). Hence, the individuals involved in the design process (and the nature and extent of their involvement) will vary from one setting to another. Clearly, the design of the team and attendant team processes are crucial determinants of the outcomes of this form of intervention.

Cohen and Bailey (1997: 243) define design factors as 'those features of the task, group, and organization that can be directly manipulated by managers to create the conditions for effective performance.' They identify three aspects of team design, namely, group composition (the characteristics of team members), task design (the organization of teamwork) and organizational context design (the link between the team and the organization in which it is embedded). Focusing on group composition and attendant facilitation processes, as opposed to organizational context design, is appropriate in the case of scenario planning because, of the various design factors that directly and indirectly influence intra-team processes and team effectiveness (e.g. shared mental models, group norms, communication, conflict), these factors are the ones most amenable to the control of designers and managers. In contrast, the organizational context is more difficult to manipulate, and thus a less appropriate design focus. Moreover, it is in the most hostile of organizational contexts that appropriate team composition and skilful facilitation are all the more critical for achieving requisite cognitive outcomes. ${ }^{2}$

The most significant team design problem facing would-be users of scenario planning techniques is to create the enabling conditions to yield the necessary forms of group information processing required to stimulate the desired cognitive outcomes. The design challenges posed by this problem are threefold. The first challenge is to configure the scenario team in ways that will ensure sufficient diversity in terms of the background knowledge and perspectives of participants to maximize the likelihood of effective group information processing. The second challenge is to configure the scenario team in ways that will ensure the requisite blend of personality characteristics among participants to maximize the likelihood of effortful, cooperative team working conducive to effective group information processing, while also minimizing the dangers of interpersonal conflict, future-focused anxiety and decisional stress that can otherwise derail the scenario planning process. The third challenge is to adapt the facilitation process to the composition of the scenario team in such a way as to maximize the likelihood of attaining the requisite cognitive outcomes. Designing appropriate facilitation processes is particularly important, since it may be politically and/or logistically difficult to configure scenario teams to possess ideal informational and personality profiles.

\section{Attaining Cognitive Goals via Elaborative Information Processing}

Van Knippenberg et al.'s (2004) recent work on group information processing has important implications for designers seeking to engineer the fundamental cognitive outcomes of scenario planning interventions. They argue that the 
elaboration of task-relevant information is the critical component of group information processing for organizational teams. Van Knippenberg et al. (2004: 1011) define elaboration as 'the exchange of information and perspectives, individuallevel processing of the information and perspectives, the process of feeding back the results of this individual-level processing into the group, and discussion and integration of its implications.' According to van der Heijden et al. (2002: 189) the benefits of scenario-based dialogue stem from participants 'challenging their own view of the world, by looking at it from other perspectives.' The notion of elaboration provides a useful concept for understanding this process.

Dialogue regarding different interpretations of cause-and-effect relations under varying plausible futures helps individuals appreciate the assumptions and beliefs of others and reflect on their own understanding of the dynamics of the strategic problems they face. Elaboration is thus the basis upon which the scenario team is able to build and test alternative representations of the strategic situation confronting the organization, which in turn serve to challenge individuals' extant mental models and build a consensus regarding appropriate strategies for responding to future contingencies.

In order to stimulate appropriate change in the mental models of the scenario team it is vital that the scenarios developed are sufficiently plausible to foster meaningful engagement, while being sufficiently challenging to test decision makers' assumptions. ${ }^{3}$ Elaboration is central to this process. The development of plausible scenarios requires team members to cross-check the internal consistency and validity of proposed causal processes by scrutinizing scenario assumptions from multiple perspectives and analysing their consistency based on others' expert knowledge. Building challenging scenarios requires that participants with different perspectives share diverse information on the drivers of change, contrast beliefs regarding causal processes, incorporate counterintuitive knowledge regarding future events, and reconcile potentially conflicting predictions from experts both within and outside the team. Elaboration is also an important mechanism for generating and evaluating robust strategic alternatives pertaining to scenarios. In short, elaboration enables teams to develop, test and challenge strategic alternatives against multiple scenarios, leading in turn to alternatives that are more robust and acceptable (see also Grinyer 2000).

\section{Designing Informationally Diverse Scenario Planning Teams}

Scenario planning teams require informational diversity in order to provide the multiplicity of perspectives necessary for elaborative information processing. Informational diversity refers to the extent to which a team possesses requisite variety in terms of the knowledge and perspectives of its members (Jehn et al. 1999). One mechanism widely advocated for attaining informational diversity in scenario teams entails bringing together individuals from a variety of backgrounds in terms of education, functional role, expertise and work experience (e.g. Grinyer 2000; Schwartz 1991; Van der Heijden 1996). Moyer's (1996) account of a major scenario planning exercise at British Airways attests to the validity of this prescription. According to Moyer, homogeneous teams 
comprising individuals drawn from common functional units with similar perspectives experienced difficulty in breaking existing frames, lacked creativity and were prone to groupthink (Janis 1982). However, a considerable volume of theory and research indicates that bringing together diverse decision makers from different parts of the organization can trigger social categorization processes, which in turn can generate subgroup bias and task and relational conflict, thereby restricting information processing (see, e.g., Jehn 1999; Pelled et al. 1999; van Knippenberg et al. 2004).

According to self/social categorization theorists (Turner 1985; Turner et al. 1987), categorizing oneself as a member of a particular organizational subgroup (e.g. functional workgroup, department or age cohort) creates an affinity and loyalty toward that subgroup (i.e. the ingroup) and its members. Individuals categorized as outgroup members (i.e. members of other salient social categories) are, in contrast, perceived less favourably than fellow ingroup members, discriminated against, and reacted to with hostility (Riek et al. 2006; Tajfel 1982). Ashforth and Mael (1989) note that, since task interdependency and interpersonal proximity are greater within than between organizational subunits, people often identify more strongly with organizational subunit identities than with a more distal and abstract organizational identity. Social categorization effects are inherent in scenario planning exercises because, in an effort to reduce the heightened sense of strategic uncertainty triggered by these events, participants are liable to cling to their subgroup identities. Anecdotal accounts reported by scenario planning practitioners illustrate the prevalence of these subgroup processes. For instance, van der Heijden et al. (2002) note that, left to their own devices, close colleagues gather together spontaneously to diagnose problems and discuss solutions (thus restricting debate to intra-subgroup dialogue), and in so doing blame dilemmas on other subgroups and align their views on strategic issues with one another. What such accounts illustrate is that an 'us and them' mentality has severe information-processing consequences, especially in situations where particular subgroups favour particular scenarios and concomitant strategic priorities (e.g. status quo strategy versus a strategy of change). The team diversity literature offers two prescriptions for configuring scenario teams to accrue the benefits of informational diversity while mitigating its deleterious effects.

First, wherever possible, designers should select team members who have worked in a variety of functional roles throughout their careers (i.e. intrapersonal functional diversity). Such individuals will be more accepting of competing perspectives and diverse ideas, and more open to considering the need for changes to the current strategy, as highlighted by the scenario analysis. Moreover, team members who readily identify with multiple (functional) subgroup identities are less likely to cling to a particular subgroup identity, thus reducing the likelihood of intergroup biases restricting elaborative information processing. Supporting these notions, Bunderson and Sutcliffe (2002) showed that management teams with high levels of intrapersonal functional diversity shared more information and performed better than those comprising members whose experience was restricted to fewer functions. Furthermore, Geletkanycz and Black's (2001) study of over 1300 executives demonstrated a significant negative relationship between intrapersonal functional diversity and commitment to the strategic 
status quo, suggesting that individuals with greater intrapersonal functional diversity will be more willing to consider new strategic directions in scenario planning exercises. Hence:

Design proposition 1: To increase the likelihood of attaining requisite forms of group information processing with informationally diverse scenario teams, wherever possible select participants with greater intrapersonal functional diversity.

Second, when seeking to design informationally diverse scenario teams by bringing together participants with different backgrounds, scenario planners should avoid introducing demographic faultlines (Lau and Murnighan 1998). Demographic faultlines are hypothetical dividing lines that split teams into competing subgroups based on patterns of group member characteristics (e.g. age, gender and function) and in so doing, heighten affective conflict and disrupt information sharing (Lau and Murnighan 2005; Li and Hambrick 2005). As an extreme example, a faultline could develop in a case where the scenario team included ten older members from finance backgrounds and ten younger members from sales/marketing backgrounds. In this case, the faultline would run along the correlated age and functional background variables, such that team members would form competing subgroups based upon within-subgroup similarity and between-subgroup differences on these characteristics. Van Knippenberg et al. (2004) argue that when multiple background characteristics converge in this way (i.e. the variables in question are correlated) social categorization effects and intergroup bias are more likely, because the differences between subgroups become more salient. Hence, when selecting scenario teams, designers should seek to minimize the likelihood of such faultlines occurring, thereby attenuating the dangers of social categorization processes and subgroup formation inimical to the elaborative processing required for successful cognitive outcomes. This entails choosing individuals whose knowledge-related background characteristics are divergent along informationally relevant dimensions. This reasoning gives rise to the following design proposition:

Design proposition 2: To increase the likelihood of attaining requisite forms of group information processing with informationally diverse scenario teams, wherever possible avoid introducing faultines within the scenario team by selecting individuals with divergent task-related background characteristics.

\section{Designing Processes to Manage Social Identity Effects in Diverse Scenario Teams}

In some circumstances it may be logistically difficult or politically infeasible to select scenario teams that possess the requisite diversity of backgrounds for informational diversity without creating faultlines. In such situations, the key to effective process design is to use facilitation techniques to manage the social identity effects that produce subgroup conflict and restrict group information processing. Such effective facilitation requires the careful manipulation of the various social identities at play within the team. The crux lies in developing and heightening the salience of a shared superordinate identity to increase team 
cohesion, without threatening the primary identities of the various subgroups represented, thereby attenuating potential inter-subgroup bias. Again, this prescription is borne out by research evidence. Van der Vegt and Bunderson (2005) found that when multidisciplinary team members possessed a sense of collective identification with their team (i.e. the superordinate identity), the expertise diversity of the team was positively related to team learning and performance, but when collective identification was low, expertise diversity was negatively related to learning and performance. Haslam et al. (2006) similarly reported that participants sharing a common social identity showed a sustained commitment to organizational change initiatives, whereas the absence of such an identity militated against commitment to change.

The common ingroup identity model of Gaertner and colleagues (1993, 1999) provides insights into mechanisms for developing shared identities within scenario teams. This model suggests that, when subgroups interact, encouraging people to consider the resulting entity as an inclusive superordinate group, rather than an aggregation of multiple distinct groups, stimulates the re-categorization of outgroup members as ingroup members and thus eclipses subgroup boundaries. The implications of this work are that to stimulate re-categorization, facilitators should structure scenario team exercises to require cooperation between members of extant subgroups, and should organize the proxemics of group activities to facilitate exchanges across subgroup boundaries (e.g. ensure the spatial location of participants crosses subgroup boundaries during discussions).

Previous research shows that identification with a new superordinate organizational identity will be stronger when team members perceive boundaries between subgroups as permeable (Ellemers et al. 1990; Terry et al. 2001). To increase the perceived permeability of intergroup boundaries, facilitators should highlight previous collaboration between the relevant subgroups represented and emphasize the overall similarities between the scenario team members. Additionally, facilitators can use team members who have occupied multiple roles in different functional areas of the organization to convey symbolically that the interests of the wider organization as a whole, as opposed to those of particular subgroups, are represented adequately.

Basic research also supports the notion that emphasizing interdependency and shared fate can engender superordinate identities, thereby mitigating subgroup bias (Gaertner et al. 1993, 1999). To develop such a sense of shared fate, facilitators can emphasize the role of participants as players on the same team by drawing attention to previous collective successes and accentuating the fact that threats are common to all. Emphasizing the shared goals of the scenario team represents a further means of increasing the salience of the superordinate group identity (Hornsey and Hogg 2000; van Knippenberg et al. 2004). A vast literature shows that shared goals benefit group cooperation and communication (for a review see Guzzo and Dickson 1996). The ultimate higher-order goal of scenario planning interventions is to ensure the long-term survival and success of the organization, while the immediate goal is to improve the flexibility of decision makers' thinking to enhance the responsiveness of the organization. In calling attention to common goals at both team and organizational levels, 
facilitators can reinforce participants' interdependences and, in so doing, heighten the salience of the scenario teams' superordinate identity.

The above line of reasoning suggests the following design proposition:

Design proposition 3: When working with an informationally diverse scenario team, to reduce inter-subgroup bias and facilitate the elaborative processing required for effective scenario construction and analysis, stimulate superordinate re-categorization by emphasizing the shared fate of the scenario team and establishing common goals.

\section{Personality Composition of Scenario Planning Teams}

Requisite informational diversity within the scenario team is a necessary but insufficient condition for achieving the elaboration central to the attainment of the desired cognitive outcomes outlined above. Scenario exercises are atypical events that entail the removal of participants from the strictures of their everyday work environments and routines, to engage in novel tasks in unfamiliar social and physical settings. Providing few dispositional cues to participants regarding appropriate behaviours, they constitute weak situations. A considerable volume of basic theory and research shows that personality traits exert strong influences on behaviour in such weak situations (see, e.g., Beaty et al. 2001; Mischel 1973).

Hodgkinson and Wright (2002) provided a stark illustration of how personality-related affective processes can derail the scenario planning process. In this case, debates concerning the potentially deleterious impact of ongoing technological innovation and industry restructuring raised levels of decisional stress and anxiety to intolerable levels. In consequence, an excessively dominant, neurotic and powerful individual (the CEO of the organization concerned) actively undermined the process, first by dominating, then by closing down, pertinent discussions. High negative affectivity, combined with a lack of consensus over the nature of the problem and potential solutions, led the wider scenario team to adopt a variety of dysfunctional coping strategies that bolstered commitment to the current failing strategy. Although several writers have acknowledged the important role personality plays in scenario planning (e.g. Mitroff et al. 1977; van der Heijden et al. 2002), neither researchers nor practitioners have addressed this issue systematically from the perspective of team design. To address these shortcomings, we distil propositions for the design of scenario teams based on the Five Factor Model (FFM) of personality.

Personality psychologists are in general agreement that five broad traits Extraversion, Neuroticism, Conscientiousness, Agreeableness, and Openness to Experience - consistently emerge across diverse contexts as key differentiators of individual functioning (see, e.g., Digman 1990; McCrae and Costa 1987). Factor analytic studies of a wide range of psychometrically robust instruments have recovered these 'Big Five' personality traits underpinning the FFM, providing powerful evidence for its validity. The compelling evidence for the biological bases and cross-cultural generalizability of the Big Five (e.g. Buss 1991; Yamagata et al. 2006) together with copious studies demonstrating systematic links between these traits and individual (e.g. Barrick and Mount 1991; Hurtz and Donovan 2000) and team (e.g. Barrick et al. 1998; Barry and Stewart 1997) 
workplace performance, mean that the FFM constitutes the most generalizable, empirically rooted and theoretically sound model of personality relevant to the functioning of work teams. ${ }^{4}$

Suitably applied to the design of scenario teams, the FFM provides an additional basis for skilfully managing the cognitive, behavioural and emotional dynamics necessary for attaining the requisite forms of open and unbiased group information processing, while coping with any attendant decisional stress and learning anxiety. In some situations, it will be possible to design the scenario team by purposively selecting an optimally configured group of participants, using psychometrically robust personality assessment techniques. Indeed, personality profiling to inform team design is now commonplace in a variety of domains (e.g. Morgeson et al. 2005). As observed earlier, however, it is sometimes logistically or politically difficult to build scenario teams with ideal personality profiles, but it is precisely in those circumstances where a detailed knowledge of individual team members' profiles is critical to enable the facilitator to shape and manage effectively the prevailing dynamics.

Table 1 describes the personality traits of the FFM, summarizes evidence relevant to their individual and group information-processing consequences, and outlines the implications of each trait for determining the optimal composition of scenario planning teams. Based on the hypothesized influences of the 'Big Five' traits on scenario planning processes, as outlined in Table 1, we offer the following propositions:

Design proposition 4: To ensure effective coping with change and willingness to explore new avenues of inquiry, and to facilitate novel thinking, the exchange of diverse perspectives and ideas, meaningful consideration of challenging scenarios and the generation of high-quality strategic responses to scenarios, wherever possible select participants high in Openness to Experience.

Design proposition 5: To facilitate elaborative information processing within the scenario team, so as to ensure the meaningful exchange of diverse perspectives and ideas and the constructive critical evaluation of scenarios and accompanying strategic responses, wherever possible select teams that comprise moderate Extraversion members, or a moderate proportion of high Extraversion members.

Design proposition 6: To maintain task focus and engagement during scenario generation and analysis and facilitate the free exchange of diverse perspectives and ideas on multiple futures and accompanying strategic responses, while minimizing defensive avoidance behaviours, wherever possible limit the involvement of high Neuroticism individuals in scenario team processes.

Design proposition 7: To facilitate open communication, a vital precursor for the reconciliation of competing perspectives regarding scenarios and the appropriateness of strategic responses, and the avoidance of groupthink, wherever possible select scenario planning teams characterized by moderately high levels of Agreeableness.

Design proposition 8: To maintain effortful engagement in scenario generation and analysis, thereby increasing the likelihood of attaining the requisite cognitive outcomes, wherever possible select participants high in Conscientiousness.

In advancing the above propositions pertaining to the role of personality, the intention is not to imply that designers of scenario planning exercises should seek to apply all of them simultaneously. Teams characterized by different personality configurations might be more or less desirable under varying circumstances. In 


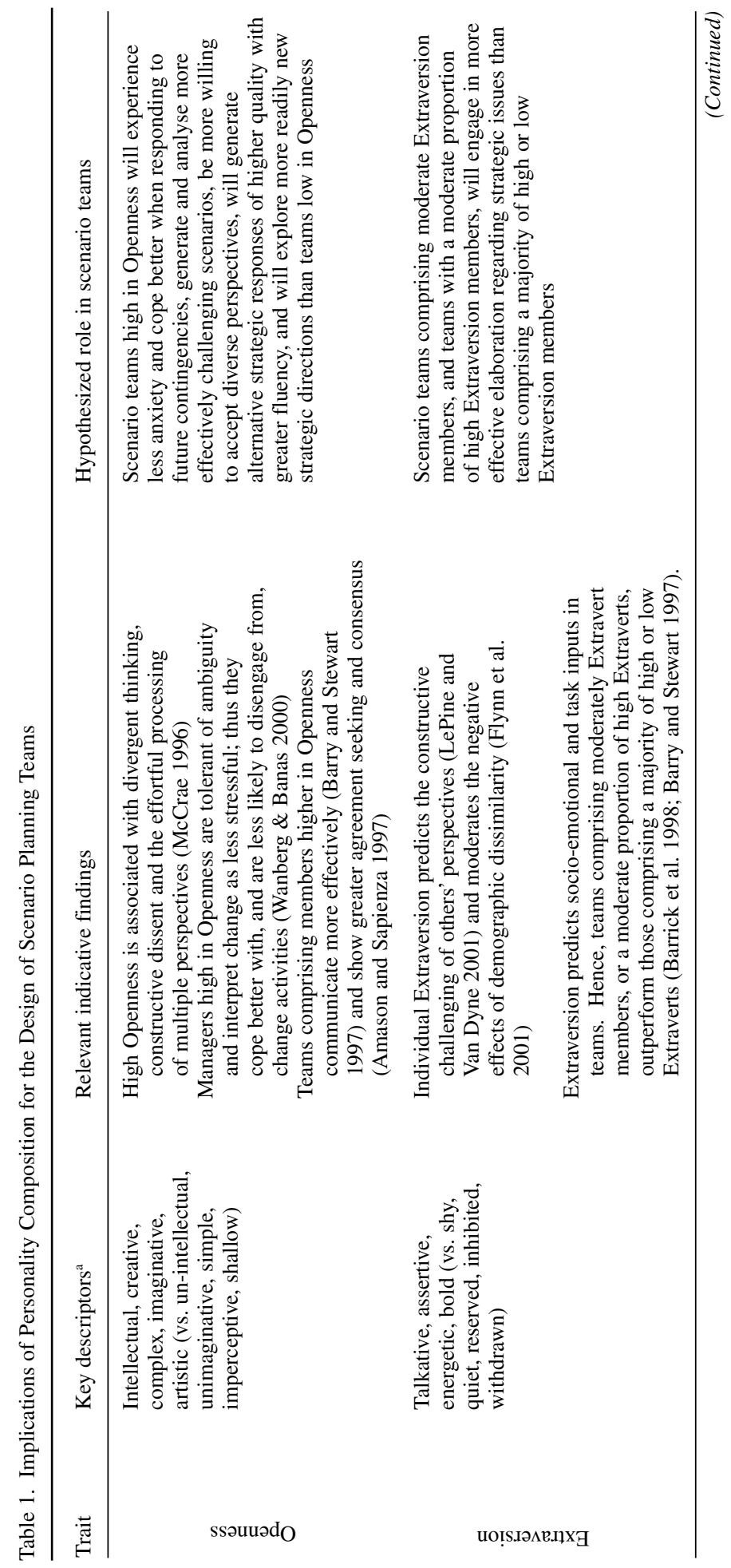




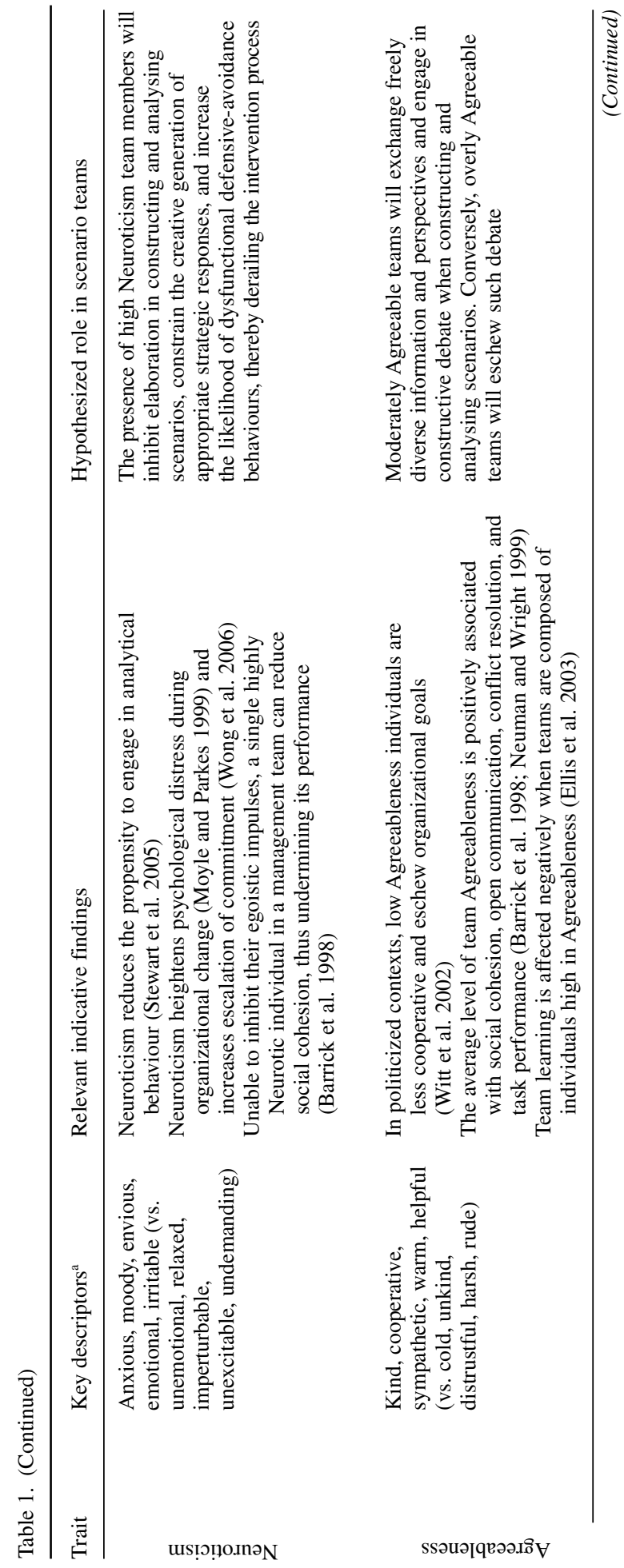




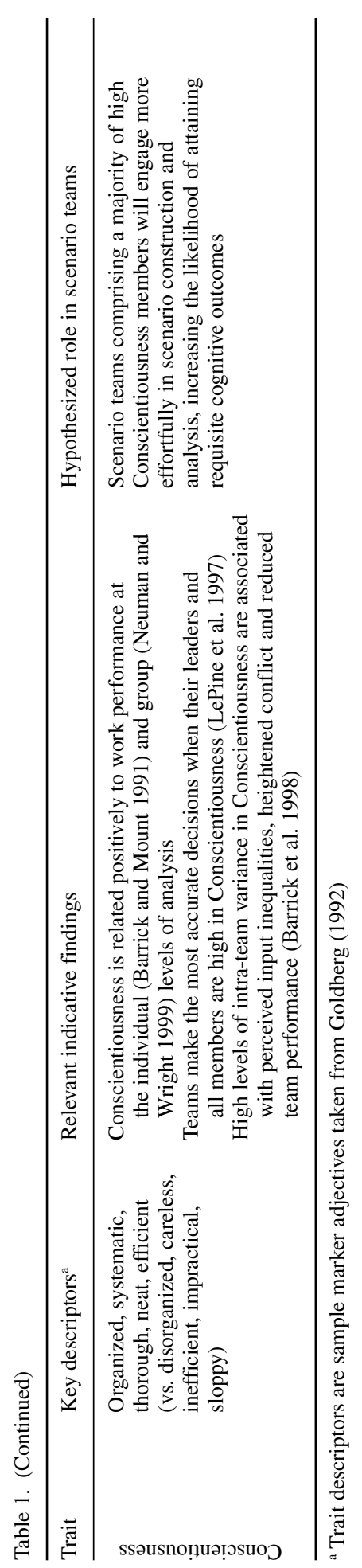


keeping with Simon's (1969) functional design ethos (i.e. designing artefacts to fit their environments), certain outcomes might be desirable in order to achieve specific goals in particular settings. For example, when using scenario planning techniques in a particularly dogmatic organizational climate, the goal of scenario planning may be explicitly to move decision makers' thinking beyond the strategic status quo by generating and analysing particularly imaginative and challenging scenarios. In such situations, it may be particularly desirable to strive for the involvement of individuals high in Openness to Experience, in an attempt to stimulate the cognitive benefits outlined above. Furthermore, as noted above, by understanding the nature and consequences of the personality composition of the team, facilitators will be in a stronger position to shape and manage the prevailing team dynamics.

\section{Adapting Facilitation and Process Design to the Personality Composition of the Scenario Team}

Personality profiling is a prerequisite for adapting facilitation techniques and process designs to the psychological makeup of the scenario team. It is opportune, then, that psychometric instruments are available for assessing potential participants' personality traits based on the FFM, which are well validated, highly reliable and easy to administer in organizational settings (e.g. Costa and McCrae 1992; Gill and Hodgkinson 2007). Armed with knowledge of team members' individual dispositions and the attendant consequences for the dynamics of the scenario team, the facilitator will be in a stronger position to manage the underlying behavioural, emotional and cognitive processes at work. Facilitators will be better equipped to engineer the requisite forms of group cognitive processes that yield changes in decision makers' mental models and enhance the flexibility of their thinking about the future, by introducing various techniques as and when appropriate.

When dealing with a scenario team comprising members low in Openness to Experience, facilitators should introduce techniques directed toward fostering innovative thinking in order to generate challenging and plausible scenarios and creative strategies for dealing with the contingencies so envisioned. The widely advocated tactic of involving so-called 'remarkable people' in scenario planning exercises (e.g. Ringland 2006; Schwartz 1991; van der Heijden 1996), external experts renowned for their radical thinking about the future, may have a particular role to play in stimulating creative thinking among low Openness scenario teams. Since low Openness individuals may cope poorly when dealing with the need for organizational change highlighted by scenario analysis, facilitators need to be mindful of potentially dysfunctional coping strategies, such as disengaging from the process. To inculcate greater involvement, facilitators should emphasize the shared fate of the team as a whole and develop and highlight shared superordinate identities and goals, as discussed above. Participants low in Openness may also struggle to comprehend others' perspectives, thus suggesting the need for facilitators to remedy this problem by actively encouraging them to consider how others' roles, goals and identities shape their beliefs regarding strategic issues (cf. Williams 2007). 
When confronted by a scenario planning team comprising a majority of high Extraversion participants, the role of the facilitator is to ensure that debate and the exchange of perspectives regarding strategic issues remains within functional levels, and does not degenerate into interpersonal conflict or levels of task conflict that might create rifts and limit meaningful dialogue. Similarly, when the team comprises a mix of high Extraversion and low Extraversion members, each perhaps with divergent knowledge bases, facilitators should purposively elicit input from the latter, ensuring that the full range of opinions are included in the scenarios and strategic responses generated, thereby increasing the diversity of perspectives considered. Conversely, in scenario teams comprising a majority of low Extraversion members (i.e. introverts), facilitators need to develop a climate of mutual trust within the scenario team, to encourage participants to be forthcoming with their opinions regarding strategic issues. The procedures outlined above for increasing the salience of a shared superordinate identity represent a useful means of fostering trust within such teams. In addition, facilitators could use dialectical inquiry (Schweiger et al. 1989) to encourage information exchange, specifically by instructing participants to scrutinize systematically the robustness of one another's assumptions underpinning particular scenarios and strategic responses.

Overcoming the dysfunctional consequences of neuroticism in scenario planning exercises is a complex problem that places considerable demands on facilitators. As discussed above, in making threats more salient these exercises can heighten anxiety among insecure decision makers. Kets de Vries and Miller (1984) outline a process for dealing with interpersonal problems stemming from managers' neurotic styles in change interventions. This process entails first identifying the problems created by neurotic individuals. In the case of scenario planning exercises, decision makers high in Neuroticism with strong ego-defensive needs might be expected to attempt to maintain control over the process by forcing other team members to accept without question their particular visions of the future, while undermining others' contributions (see Hodgkinson and Wright 2002). Following the identification of the triggers and underlying causes of neurotic behaviour, Kets de Vries and Miller (1984) suggest two strategies for dealing with the attendant interpersonal problems. The first entails limiting the involvement of highly neurotic individuals in the change process, or changing the context in which they are involved (e.g. moving individuals out of conflict-laden discussions), but this may be difficult in scenario planning exercises for political reasons, as observed above. The second strategy involves using insight-oriented and supportive facilitation techniques to reduce decision makers' anxiety about the future. Insight-oriented techniques entail encouraging decision makers to reassess their feelings and behaviours toward others, in an attempt to foster recognition of the sources and consequences of conflict. In contrast, supportive facilitation techniques involve using reassurance, inspiration and persuasion in an effort to change dysfunctional patterns of behaviour (for a detailed discussion of these strategies, see Kets de Vries and Miller 1984).

When facilitating scenario planning exercises with low Agreeableness teams or with teams uncommitted to the process (i.e. those comprising a majority of low Conscientiousness participants), emphasizing a superordinate identity and shared goals and fates are again important techniques for reducing the likelihood of inter- 
personal and subgroup conflict within the team. In contrast, undertaking scenario planning with teams high in Agreeableness may require the introduction of techniques such as devil's advocacy to stimulate decision makers to challenge one another's assumptions about the organization's future (Schweiger et al. 1989).

\section{Concluding Remarks}

According to Simon (1969), effective design science requires scientific understanding of general causal mechanisms and knowledge of how these apply in specific contexts of application. With reference to the case of scenario planning, we have demonstrated how, by drawing on well-established bodies of basic theory and research germane to the design goals at hand, researchers can develop robust design principles and propositions in situations where the prevailing evidence base underpinning current design attempts is otherwise limited. In so doing, our approach has led to practical design propositions grounded in 'generative mechanisms' (van Aken 2004) deduced from theory and evidence located in the wider social and organizational sciences. Cognizant of how team composition and attendant facilitation processes influence the forms of information processing capable of stimulating requisite cognitive change, designers should now be in a stronger position to maximize the chances of successful outcomes in future scenario planning exercises. In illustrating how it is possible to develop a deeper understanding of how controllable design features influence the causal mechanisms that bring about desired outcomes, our approach provides the basis for designers to maximize the likelihood of successful design attempts overall, i.e. beyond applications to scenario planning per se.

What this article demonstrates overall is the potential of our approach to develop design principles and propositions that draw upon existing basic theory and research as a starting point for the design process, rather than embarking upon an extensive portfolio of problem-specific empirical studies in the focal context of application. Clearly, an important next step is to subject the particular design propositions enumerated above to field-testing, in order to ascertain what works and what does not work, along the lines indicated by van Aken (2004, 2005) and Romme and Endenberg (2006).

Design propositions such as those enumerated above can act as boundary objects to communicate meaning between social science research and the design process, thus helping to close the gap between basic research and practice (cf. van Aken 2004, 2005). As observed by Romme and Endenburg (2006: 295), 'boundary objects can serve as a conceptual framework for productive interaction and collaboration between practitioners, consultants, and academics.' By continuing design efforts without reference to boundary objects that confer the necessary insights from basic theory and research, designers run the risk of perpetuating potentially suboptimal designs and ineffective practices, i.e. ones informed only by the received wisdom of 'insider' practitioners.

As noted at the outset, the primary literature on scenario planning is replete with case studies of successful applications, written primarily by practising advocates. Although such reports are helpful from an advocacy standpoint, many 
of the principles enumerated in these cases are based on little more than anecdotal evidence. Such evidence is clearly unsuitable for the purposes of systematic review and related evidence-informed approaches to design science, along the lines advocated by Tranfield et al. (2003). The scenario planning literature is a long way from being sufficiently mature to provide the basis for such evidenceinformed approaches to the design of future interventions. We hope, however, that the design propositions distilled above have accelerated progress toward this goal, having circumvented the requirement for many years of additional primary research targeted directly to the application of scenario-based interventions (cf. Romme and Endenburg 2006). This is not to imply that the propositions distilled in this article are without the need for further refinement. Rather, as noted above, they provide a reliable starting point for future practical experimentation with alternative designs in a variety of organizational settings (Romme and Endenburg 2006; van Aken 2004, 2005). However, interventions based upon the propositions enumerated should also be subjected to the rigours of formal evaluation, preferably in the mode of outsider inquiry, so as not to perpetuate the accumulation of received wisdom of questionable reliability and validity (Evered and Louis 1981). In short, our design propositions are amenable to falsification; they can and should be tested readily in future practical and scientific endeavours, in keeping with the central tenets of pragmatic science.

Anderson et al. (2001) introduced the notion of 'Pragmatic Science' to differentiate work that is not only highly rigorous but also highly relevant to the wider consumers of knowledge from that which is highly relevant but low in terms of rigour (Popularist Science), highly rigorous but low in terms of relevance (Pedantic Science), and low in terms of rigour and relevance (Puerile Science). In our view, Pragmatic Science as defined by Anderson et al. is design science par excellence. In bringing a design science perspective to bear on scenario planning, what we have ultimately sought to achieve is to elevate the evidence base for this common management practice from the domain of Popularist Science into the domain of Pragmatic Science.

\section{Notes}

We are grateful to Georges Romme and four anonymous referees of Organization Studies for their helpful comments and constructive suggestions on earlier drafts. The financial support of the UK ESRC/EPSRC Advanced Institute of Management (AIM) Research in the preparation of this article (under grant number RES-331-25-0028) is also gratefully acknowledged.

1 The scenario planning literature does not clearly define the mental models notion. In the remainder of this article, we use the term mental model to denote an internal representation of entities and the relations between them that 'mirrors the relevant aspects of the corresponding state of affairs in the world' (Johnson-Laird 1980: 98).

2 Although this article focuses on the specific design challenges associated with the attainment of requisite cognitive outcomes, we recognize that the links between these proximal outcomes and more distal outcomes associated with wider organizational adaptation present a further important design challenge. However, research directed toward the attainment of this goal is in its infancy (see, e.g., Bourque and Johnson 2008; Hodgkinson et al. 2006) and thus constitutes an inadequate basis upon which to distil robust design propositions.

3 A large volume of work in social cognition shows that scenarios only garner engagement and stretch thinking when they are plausible, and that, conversely, implausible scenarios are considered irrelevant and typically fail to challenge prior beliefs. However, since highly plausible scenarios by definition exhibit tight fitness with prior knowledge they may be inadequate to stimulate changes in extant mental models. Consequently, scenarios must also be sufficiently challenging to engender cognitive change (for a more detailed review of the cognitive underpinnings of multiple scenario analysis, see Healey and Hodgkinson 2008). 
4 Whereas the Big Five model was derived from lexical data, and thus constitutes a descriptive model of personality attributes, the FFM has a dispositional basis that posits underlying biological determinants of the five factors; as such, it constitutes an explanatory model. Hence, they are not synonymous (for further details, see Gill and Hodgkinson 2007).

\section{References}

Amason, A. C., and H. J. Sapienza

1997 'The effects of top management team size and interaction norms on cognitive and affective conflict'. Journal of Management 23: 495-516.

Anderson, N, P. Herriot, and G. P. Hodgkinson

2001 'The practitioner-researcher divide in Industrial, Work and Organizational (IWO) psychology: Where are we now, and where do we go from here?' Journal of Occupational and Organizational Psychology 74: 391-411.

Ashforth, B. E., and F. Mael

1989 'Social identity theory and the organization'. Academy of Management Review 14: 20-39.

Barr, P. S., J. L. Stimpert, and A. S. Huff

1992 'Cognitive change, strategic action, and organizational renewal'. Strategic Management Journal 13: 15-36.

Barrick, M. R., and M. K. Mount

1991 'The big 5 personality dimensions and job-performance: A metaanalysis'. Personnel Psychology 44: $1-26$.

Barrick, M. R., G. L. Stewart, M. J. Neubert, and M. K. Mount

1998 'Relating member ability and personality to work-team processes and team effectiveness'. Journal of Applied Psychology 83: 377-391.

Barry, B., and G. L. Stewart

1997 'Composition, process, and performance in self-managed groups: The role of personality. Journal of Applied Psychology 82: 62-78.

Beaty, J. C., J. N. Cleveland, and K. R. Murphy

2001 'The relation between personality and contextual performance in strong versus weak situations'. Human Performance 14: 125-148.

Boland, R. J., and F. Collopy, editors 2004 Managing as designing. Stanford,
CA: Stanford University

Press.

Bourque, N., and G. Johnson

2008 'Strategy workshops and "away-days" as ritual' in The Oxford handbook of organizational decision making. G. P. Hodgkinson and W. H. Starbuck (eds) 552-564. Oxford: Oxford University Press (in press).

Bunderson, J. S., and K. M. Sutcliffe

2002 'Comparing alternative conceptualizations of functional diversity in management teams: Process and performance effects'. Academy of Management Journal 45: 875-893.

Buss, D. M.

1991 'Evolutionary personality psychology'. Annual Review of Psychology 42: 459-491.

Cohen, S. G., and D. E. Bailey

1997 'What makes teams work: Group effectiveness research from the shop floor to the executive suite'. Journal of Management 23: 239-290.

Costa, P. T., and R. R. McCrae

1992 The NEO PI-R professional manual. Odessa, FL: Psychological Assessment Resources.

De Geus, A. P.

1988 'Planning as learning'. Harvard Business Review 66: 70-74.

Digman, J. M.

1990 'Personality structure: Emergence of the 5-Factor Model'. Annual Review of Psychology 41: 417-440.

Dunbar, R. L. M., and W. H. Starbuck

2006 'Learning to design organizations and learning from designing them'. Organization Science 17: 171-178.

Eden, C., and F. Ackermann

1998 Making strategy: The journey of strategic management. London: Sage Publications.

Ellemers, N., A. van Knippenberg, and H. Wilke

1990 'The influence of permeability of group boundaries and stability of 
group status on strategies of individual mobility and social change'. British Journal of Social Psychology 29: 233-246.

Ellis, A. P. J., J. R. Hollenbeck, D. R. Ilgen, C. Porter, B. J. West, and H. Moon 2003 'Team learning: Collectively connecting the dots'. Journal of Applied Psychology 88: 821-835.

Evered, R., and M. R. Louis

1981 'Alternative perspectives in the organizational sciences: "Inquiry from the inside" and "inquiry from the outside". Academy of Management Review 6: 385-395.

Flynn, F. J., J. A. Chatman, and S. E. Spataro

2001 'Getting to know you: The influence of personality on impressions and performance of demographically different people in organizations'. Administrative Science Quarterly 46: 414-442.

Gaertner, S. L., J. Dovidio, P. A. Anastasio, B. A. Bachman, and M. C. Rust 1993 'The common ingroup identity model: Recategorization and the reduction of intergroup bias' in European Review of Social Psychology. W. Stroebe, and M. Hewstone (eds), 1-26. London: Wiley.

Gaertner, S. L., J. F. Dovidio, M. C. Rust, J. A. Nier, B. S. Banker, C. M. Ward, G. R. Mottola, and M. Houlette

1999 'Reducing intergroup bias: Elements of intergroup cooperation'. Journal of Personality and Social Psychology 76: 388-402.

Geletkanycz, M. A., and S. S. Black

2001 'Bound by the past? Experiencebased effects on commitment to the strategic status quo'. Journal of Management 27: 3-21.

Gill, C. M., and G. P. Hodgkinson

2007 'Development and validation of the Five-Factor Model Questionnaire (FFMQ): An adjectival-based personality inventory for use in occupational settings'. Personnel Psychology 60: 731-766.

Goldberg, L. R.

1992 'The development of markers for the Big-Five factor structure'. Psychological Assessment 4: 26-42.
Grinyer, Peter H.

2000 'A cognitive approach to group strategic decision taking: A discussion of evolved practice in the light of received research results'. Journal of the Operational Research Society 51: 21-35.

Guzzo, R. A., and M. W. Dickson

1996 'Teams in organizations: Recent research on performance and effectiveness'. Annual Review of Psychology 47: 307-338.

Haslam, S. A., M. K. Ryan, T. Postmes, R. Spears, J. Jetten, and P. Webley

2006 'Sticking to our guns: social identity as a basis for the maintenance of commitment to faltering organizational projects'. Journal of Organizational Behavior 27: 607-628.

Healey, M. P., and G. P. Hodgkinson 2008 'Troubling futures: Scenarios and scenario planning for organizational decision making' in The Oxford handbook of organizational decision making. G. P. Hodgkinson and W. H. Starbuck (eds), 565-585. Oxford: Oxford University Press (in press).

Hodgkinson, G. P.

1997 'Cognitive inertia in a turbulent market: The case of UK residential estate agents'. Journal of Management Studies 34: 921-945.

Hodgkinson, G. P., and G. Wright

2002 'Confronting strategic inertia in a top management team: Learning from failure'. Organization Studies 23: 949-977.

Hodgkinson, G. P., R. Whittington, G. Johnson and M. Schwarz

2006 'The role of strategy workshops in strategy development processes: Formality, communication, coordination and inclusion'. Long Range Planning 39: 479-496.

Hornsey, M. J., and M. A. Hogg

2000 'Assimilation and diversity: An integrative model of subgroup relations'. Personality and Social Psychology Review 4: 143-156.

Hurtz, G. M., and J. J. Donovan

2000 'Personality and job performance: The big five revisited'. Journal of Applied Psychology 85: 869-879.

Janis, I. L.

1982 Groupthink. Boston, MA: HoughtonMifflin. 
Jehn, K. A., G. B. Northcraft, and M. A. Neale

1999 'Why differences make a difference: A field study of diversity, conflict, and performance in workgroups'. Administrative Science Quarterly 44: 741-763.

Johnson-Laird, P. N.

1980 'Mental models in cognitive science'. Cognitive Science 4: 71-115.

Kets de Vries, M. F. R., and D. Miller

1984 The neurotic organization. San Francisco: Jossey-Bass.

Lau, D. C., and J. K. Murnighan

1998 'Demographic diversity and faultlines: The compositional dynamics of organizational groups'. Academy of Management Review 23: 325-340.

Lau, D. C., and J. K. Murnighan

2005 'Interactions within groups and subgroups: The effects of demographic faultlines'. Academy of Management Journal 48: 645-659.

LePine, J. A. and L. Van Dyne

2001 'Voice and cooperative behavior as contrasting forms of contextual performance: Evidence of differential relationships with big five personality characteristics and cognitive ability'. Journal of Applied Psychology 86: 326-336.

LePine, J. A., J. R. Hollenbeck, D. R. Ilgen, and $\mathrm{J}$. Hedlund

1997 'Effects of individual differences on the performance of hierarchical decision-making teams: Much more than g'. Journal of Applied Psychology 82: 803-811.

Li, J. T., and D. C. Hambrick

2005 'Factional groups: A new vantage on demographic faultlines, conflict, and disintegration in work teams'.

Academy of Management Journal 48: 794-813.

Linneman, R. E., and H. E. Klein

1983 'The use of multiple scenarios by united-states industrial companies: A comparison study, 1977-1981. Long Range Planning 16: 94-101.

Malaska, P.

1985 'Multiple scenario approach and strategic behavior in European companies'. Strategic Management Journal 6: 339-355.
McCrae, R. R.

1996 'Social consequences of experiential openness'. Psychological Bulletin 120: 323-337.

McCrae, R. R., and P. T. Costa

1987 'Validation of the 5-factor model of personality across instruments and observers'. Journal of Personality and Social Psychology 52: 81-90.

Mischel, W.

1973 'Toward a cognitive social learning reconceptualization of personality'. Psychological Review 80: 252-283.

Mitroff, I. I., V. P. Barabba, and

R. H. Kilmann

1977 'The application of behavioral and philosophical technologies to strategic planning: A case study of a large federal agency'. Management Science 24: 44-58.

Morgeson, F. P., M. H. Reider, and M. A. Campion

2005 'Selecting individuals in team settings: The importance of social skills, personality characteristics, and teamwork knowledge'. Personnel Psychology 58: 583-611.

Moyer, K.

1996 'Scenario planning at British Airways: A case study'. Long Range Planning 29: 172-181.

Moyle, P., and K. Parkes

1999 'The effects of transition stress: a relocation study'. Journal of Organizational Behavior 20: 625-646.

Neuman, G. A., and J. Wright

1999 'Team effectiveness: Beyond skills and cognitive ability'. Journal of Applied Psychology 84: 376-389.

Pelled, L. H., K. M. Eisenhardt, and K. R. Xin

1999 'Exploring the black box: An analysis of work group diversity, conflict, and performance'. Administrative Science Quarterly 44: 1-28.

Reger, R. K., and T. B. Palmer

1996 'Managerial categorization of competitors: Using old maps to navigate new environments'. Organization Science 7: 22-39.

Riek, B. M., E. W. Mania, and S. L. Gaertner

2006 'Intergroup threat and outgroup attitudes: A meta-analytic review'. Personality and Social Psychology Review 10: 336-353. 
Ringland, G.

2006 Scenario planning: Managing for the Future, 2nd edn. Chichester, UK: Wiley.

Romme, A. G. L., and G. Endenburg

2006 'Construction principles and design rules in the case of circular design'. Organization Science 17: 287-297.

Russo, J. E., and P. J. H. Schoemaker

1992 'Managing overconfidence'. Sloan Management Review 33: 7-17.

Schein, E. H.

1987 The clinical perspective in fieldwork. Newbury Park, CA: Sage Publications.

Schoemaker, P. J. H.

1993 'Multiple scenario development: Its conceptual and behavioral foundation'. Strategic Management Journal 14: 193-213.

Schwartz, P.

1991 The art of the long view. New York: Currency Doubleday.

Schweiger, D. M., W. R. Sandberg, and P. L. Rechner

1989 'Experiential effects of dialectical inquiry, devils advocacy, and consensus approaches to strategic decision-making'. Academy of Management Journal 32: 745-772.

Simon, H. A.

1969 The sciences of the artificial. Cambridge, MA: MIT Press.

Stewart, G. L, I. S. Fulmer, and M. R. Barrick

2005 'An exploration of member roles as a multilevel linking mechanism for individual traits and team outcomes'. Personnel Psychology 58: 343-365.

Tajfel, $\mathrm{H}$.

1982 'The social psychology of intergroup relations'. Annual Review of Psychology 33: 1-39.

Tajfel, H., and J. C. Turner

1979 'An integrative theory of inter-group conflict, in The social psychology of intergroup relations. W. G. Austin and S Worchel (eds), 33-47. Monterey, CA: Brooks-Cole.

Terry, D. J., C. J. Carey, and V. J. Callan

2001 'Employee adjustment to an organizational merger: An intergroup perspective'. Personality and Social Psychology Bulletin 27: 267-280.
Tranfield, D., D. Denyer, and P. Smart

2003 'Towards a methodology for developing evidence-informed management knowledge by means of systematic review'. British Journal of Management 14: 207-222.

Turner, J. C.

1985 'Social categorization and the selfconcept: A social cognitive theory of group behavior' in Advances in group processes. E. J. Lawler (ed.), 77-122. Greenwich, CT: JAI Press.

Turner, J. C., M. A. Hogg, E. J. Oakes, S. D. Reicher, and M. S. Wetherell

1987 Rediscovering the social group: A self-categorization theory. Oxford: Blackwell.

van Aken, J. E.

2004 'Management research based on the paradigm of the design sciences: The quest for field-tested and grounded technological rules'. Journal of Management Studies 41: 219-246.

van Aken, J. E.

2005 'Management research as a design science: Articulating the research products of mode 2 knowledge production in management'. British Journal of Management 16: 19-36.

van der Heijden, K.

1996 Scenarios: The art of strategic conversation. Chichester, UK: John Wiley.

van der Heijden, K., R. Bradfield, G. Burt, G. Cairns, and G. Wright

2002 The sixth sense: Accelerating organizational learning with scenarios. New York: John Wiley.

Van der Vegt, G. S., and J. S. Bunderson

2005 Learning and performance in multidisciplinary teams: The importance of collective team identification. Academy of Management Journal 48: 532-547.

van Knippenberg, D., C. K. W. De Dreu, and A. C. Homan

2004 'Work group diversity and group performance: An integrative model and research agenda'. Journal of Applied Psychology 89: 1008-1022.

Wack, P.

1985a 'Scenarios: Uncharted waters ahead'. Harvard Business Review 63: 72-89. 
Wack P.

1985b 'Scenarios: Shooting the rapids. Harvard Business Review 63: 139-150.

Wanberg, C. R., and J. T. Banas

2000 'Predictors and outcomes of openness to changes in a reorganizing workplace'. Journal of Applied Psychology 85: 132-142.

Williams, M.

2007 'Building genuine trust through interpersonal emotion management: A threat regulation model of trust and collaboration across boundaries'. Academy of Management Review 32: 595-621.

Witt, L. A., K. M. Kacmar, D. S. Carlson, and S. Zivnuska

2002 'Interactive effects of personality and organizational politics on contextual performance'. Journal of

Organizational Behavior 23: 911-926.

Wong, K. F. E, M. Yik, and J. Y. Y. Kwong

2006 'Understanding the emotional aspects of escalation of commitment: The role of negative affect'. Journal of Applied Psychology 91: 282-297.

Yamagata, S., A. Suzuki, J. Ando, Y. Ono, N. Kijima, K. Yoshimura, F. Ostendorf, A. Angleitner, R. Riemann, F. M. Spinath, W. J. Livesley, and K. L. Jang

2006 'Is the genetic structure of human personality universal? A crosscultural twin study from North America, Europe, and Asia'. Journal of Personality and Social Psychology 90: 987-998.

\section{Gerard P. Hodgkinson}

Mark P. Healey
Gerard P. Hodgkinson is Professor of Organizational Behaviour and Strategic Management, a Senior Fellow of the UK ESRC/EPSRC Advanced Institute of Management (AIM) Research, and Director of the Centre for Organizational Strategy, Learning and Change at the University of Leeds, UK. The (co-)author of three books and over 50 scholarly journal articles and chapters in edited books, his research focuses on the analysis of cognition in organizations and applied psychometrics, including the development and psychometric evaluation of methods for eliciting and representing organizational actors' mental representations and instruments for the assessment of individual differences in the workplace. His work has appeared in a number of outlets including the Annual Review of Psychology, Organizational Research Methods, Personnel Psychology and Strategic Management Journal. A Fellow of both the British Psychological Society and the British Academy of Management, he was the Editor-inChief of the British Journal of Management (1999-2006) and currently co-edits the International Review of Industrial and Organizational Psychology and serves on several editorial boards including the Academy of Management Review and Organization Science.

Address: Centre for Organizational Strategy, Learning and Change, Leeds University Business School, University of Leeds, Leeds LS2 9JT, UK.

Email: gph@lubs.leeds.ac.uk

Mark P. Healey is a Research Fellow of the UK ESRC/EPSRC Advanced Institute of Management (AIM) Research and a Senior Research Fellow in Organizational Psychology at the Centre for Organizational Strategy, Learning and Change, University of Leeds, UK. He received his PhD in management sciences from UMIST. His current research focuses on managerial and organizational cognition, particularly the individual and group cognitive processes that underpin decision making, strategizing and adaptation at the individual, team and organizational levels of analysis. His research with AIM is examining the influence of individuals' mental representations on cognitive and organizational inertia and adaptation, and the efficacy of various techniques directed toward overcoming cognitive barriers to change.

Address: Centre for Organizational Strategy, Learning and Change, Leeds University Business School, University of Leeds, Leeds LS2 9JT, UK.

Email: busmph@leeds.ac.uk 